\title{
Pregnancy and lactation associated osteoporosis: unrecognized cause of musculoskeletal pain syndrome during the peri-pregnancy period
}

\author{
Anna Kornete*, Ingvars Rasa, Maija Mukane
}

Latvian Osteoporosis and Metabolic Bone Diseases Association, Rīga Stradiņš University, Riga, Latvia

Received: 17 April 2017

Accepted: 18 May 2017

\section{*Correspondence:}

Dr. Anna Kornete,

E-mail: annakornete@gmail.com

Copyright: (C) the author(s), publisher and licensee Medip Academy. This is an open-access article distributed under the terms of the Creative Commons Attribution Non-Commercial License, which permits unrestricted non-commercial use, distribution, and reproduction in any medium, provided the original work is properly cited.

\begin{abstract}
Pregnancy- and lactation-associated osteoporosis (PLO) is a rare disorder, usually occurring in late pregnancy and the early post-partum period. The prevalence, etiology, pathogenesis and therapy remains unclear. Three clinical cases of PLO present patients with multiple severe osteoporotic fractures during the peri-pregnancy period and different treatment strategies.
\end{abstract}

Keywords: Fractures, Lactation, Osteoporosis, Pregnancy

\section{INTRODUCTION}

Pregnancy- and lactation-associated osteoporosis (PLO) is a rare syndrome characterized by significant changes in calcium and bone homeostasis during pregnancy and the early post-partum period. ${ }^{1}$ At this time, calcium demands are increased to meet the needs of the growing fetus and the losses that occur during lactation. ${ }^{1,2}$

PLO leads to musculoskeletal pain syndrome, fragile bones and increased risk of fractures during late pregnancy and early post-partum period. ${ }^{1.3}$ The three case reports present the clinical findings of young women who developed severe PLO with vertebral fractures during a peri-pregnancy period.

\section{CASE REPORT}

We came across a 34-year-old primiparous woman with severe lower back pain that worsened two months after a Cesarean delivery. Her height was $168.5 \mathrm{~cm}$, body weight was $62 \mathrm{~kg}$, and BMI was $21.7 \mathrm{~kg} / \mathrm{m}^{2}$. A CT scan exhibited multiple vertebral osteoporotic fractures of the thoracic (Th11, Th12) and lumbar (L1, L2) spine (Figure $1)$.

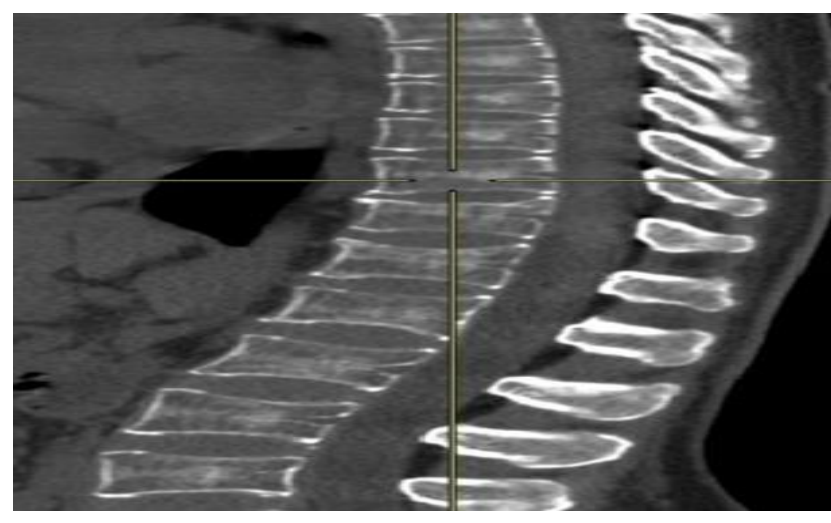

Figure 1: A CT scan of the thoracic and lumbar spine in case 1.

The lumbar spine bone mineral density (BMD) was measured using dual x-ray absorptiometry (DXA) and was below the expected range of age $(-2.7 \mathrm{SD})$. The patient had serum 25-hydroxyvitamin D (25(OH)D) 
deficiency $(11.5 \mathrm{ng} / \mathrm{mL})$. Biochemical markers of bone turnover were increased: osteocalcin level was 52.8 $\mathrm{ng} / \mathrm{ml}$, cross-linked C-terminal telopeptide of type I collagen $(\beta$ CTX) level was $0.766 \mathrm{ng} / \mathrm{mL}$. The laboratory assessments (including complete blood count, calcium, total blood cholesterol, low-density lipoprotein cholesterol, liver enzymes, alkaline phosphatase, creatinine, parathyroid hormone, protein electrophoresis) revealed no abnormality.

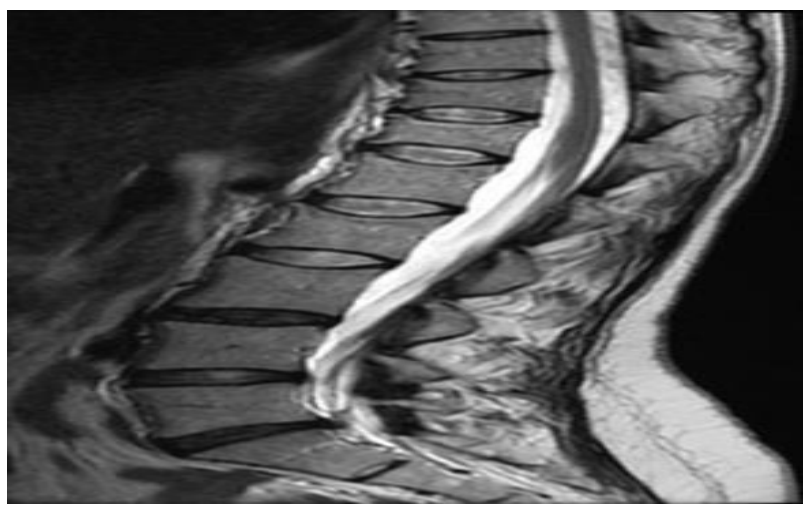

Figure 2: A MRI scan of the thoracic and lumbar spine in case 2 .

We also encountered a 29-year-old patient with musculoskeletal pain syndrome began in the third trimester of pregnancy and deteriorated immediately post-partum. Her height was $162 \mathrm{~cm}$, body weight was 57 $\mathrm{kg}$, and BMI was $21.8 \mathrm{~kg} / \mathrm{m}^{2}$. MRI scan showed vertebral compressions of the thoracic (Th11, Th12) and lumbar (L1) spine, osteoporotic fracture of the L2 vertebra (Figure 2). The lumbar spine BMD was measured using DXA and was below the expected range of age $(-4.5$ SD). The white blood cells count was decreased (3.370/ $\mu \mathrm{L})$ and $25-\mathrm{OH}$ vitamin D level was slightly decreased (21.6 ng/mL). Osteocalcin level and $\beta$ CTX level was increased $56.6 \mathrm{ng} / \mathrm{ml}$ and $0.759 \mathrm{ng} / \mathrm{ml}$, respectively. The red blood cells, platelets, calcium, liver enzymes, reactive protein, thyroid function tests, prolactin, alkaline phosphatase, protein electrophoresis revealed normal findings.

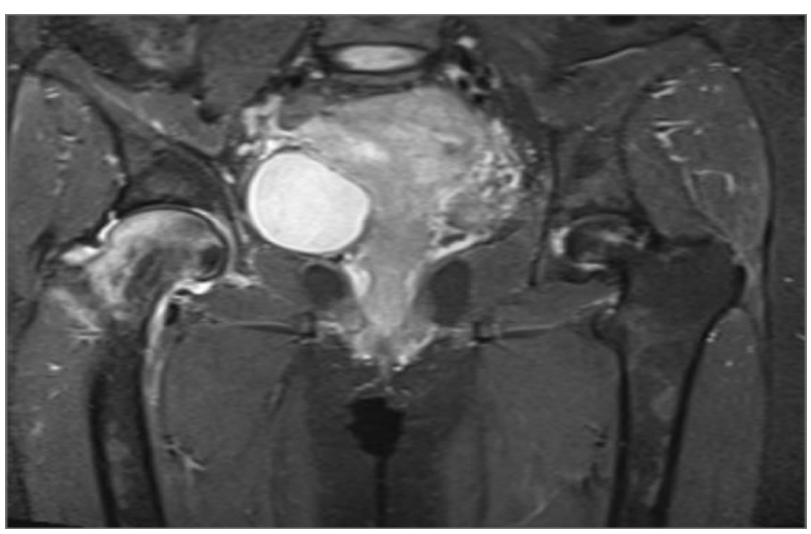

Figure 3: A MRI of the pelvic bones in case 3.
Finally, we report a case of a 35-years-old patient with complaints of progressive pain in the back, hip and right lower extremity, accompanied by reduced general mobility. Her height was $166 \mathrm{~cm}$, body weight was $58 \mathrm{~kg}$, and BMI was $20.0 \mathrm{~kg} / \mathrm{m}^{2}$. MRI revealed multiple sacral and femoral osteoporotic fractures. The lumbar spine and femoral BMD was below the expected range of age $(-3.9$ $\mathrm{SD},-3.6 \mathrm{SD},-2.8 \mathrm{SD}$, respectively). The laboratory assessments (including the $25(\mathrm{OH}) \mathrm{D}$ vitamin, osteocalcin, $\beta$ CTX) showed no abnormality. Neither of patients had any disease or other osteoporosis risk factors.

\section{DISCUSSION}

All the patients were diagnosed with PLO, and an appropriate treatment was initiated. As the etiology and pathogenesis of PLO remain incomprehensible, there is no mutually agreed opinion in the management of this condition. ${ }^{4}$ The aim of therapy was to increase BMD and prevent new fractures and the development of chronic pain. Patients were primarily recommended to discontinue breastfeeding, maintain a balanced diet and rest.

Patients were administered with vitamin D supplementation (5000 IU/day) and calcium (500 $\mathrm{mg} /$ day). For pain management, nonsteroidal antiinflammatory drugs and muscle strengthening exercises, and the thoracolumbar corset was recommended to all the patients. In case 1 daily injection of teriparatide for 10 months was used. In case 2 once-yearly infusion of zoledronic acid and L2 vertebroplasty was performed. In case 3 ibandronic acid injection every three months for two times was conducted.

PLO involves bone loss, but the process does not increase susceptibility to osteoporosis in the long term. ${ }^{5}$ However, the transitory reduction in bone mass may pose some women at risk, possibly as a result of the previous osteopenia. $^{1,5}$

\section{CONCLUSION}

PLO, although a rare disorder and often confused with other causes of lower back pain associated with pregnancy and lactation, should be kept in mind when a new and expecting mother develops persistent back pain. PLO can result in devastating physical, psychosocial and economic consequences, thus monitoring the patients with risk factors or secondary causes of osteoporosis, early diagnosis and management are essential for increasing the quality of life. Different treatment strategies equally well help to reach targets of the therapy in cases of PLO: increase BMD, prevent chronic pain and new fractures and improve a quality of life.

Funding: No funding sources

Conflict of interest: None declared

Ethical approval: Not required 


\section{REFERENCES}

1. Sanz-Salvador L, Garcia-Perez MA, Tarin JJ, Cano A. Bone metabolic changes during pregnancy: a period of vulnerability to osteoporosis and fracture. Eur J Endocrinol. 2015;172:53-65.

2. Nakamura Y, Kamimura M, Shota I, Keijiro M, Masatoshi K, Shigeharu U, Hiroyuki K. A case series of pregnancy- and lactation-associated osteoporosis and a review of the literature. Ther Clin Risk Managm. 2015;11:1361-5.

3. Raffaeta G, Mazzantini M, Menconi A, Bottai A, Falossi F, Celauro I, Guido G. Osteoporosis with vertebral fractures associated with pregnancy: two case reports. Clin Cases Miner Bone Metab. 2014;11:136-8.
4. Seok HL, Moon-Ki H, Seung WP, Hyoung-Moo P, Jaetaek K, Jihyun A. A Case of Teriparatide on Pregnancy-Induced Osteoporosis. J Bone Metab. 2013;20:111-4.

5. Iwamoto J, Yoshihiro S, Mitsuyoshi U, Hideo M. Five-year follow-up of a woman with pregnancy and lactation-associated osteoporosis and vertebral fractures. Ther Clin Risk Managm. 2012;8:195-9.

Cite this article as: Kornete A, Rasa I, Mukane M. Pregnancy and lactation associated osteoporosis: unrecognized cause of musculoskeletal pain syndrome during the peri-pregnancy period. Int $\mathbf{J}$ Reprod Contracept Obstet Gynecol 2017;6:3160-2. 